УДК 539.3

DOI: $10.15587 / 2313-8416.2015 .37060$

\title{
К ОПРЕДЕЛЕНИЮ ПРЕДЕЛЬНОГО СОСТОЯНИЯ ТРЕХСЛОЙНОГО ЦИЛИНДРА С ВЯЗКИМ НАПОЛНИТЕЛЕМ
}

\author{
(C) Хейрабади Газаля Сабир кызы
}

В работе определено напряжено-деформированное состояние трехслойного ичлиндра, внутренний слой которого является стальным, средний слой - вязко упругим, антикоррозионным и внешний слой, который является защчитным слоем из полимерного материала. Определены значения внутренних и внешних давлений, приводящих к разрушению слоев

Ключевые слова: антикоррозионное покрытие, перемещение, деформация, напряжение, давление, слой, условие разрушения

In the article it is determined strained and deformed state of the three-layer cylinder, the inner layer of which is steel, the middle layer is visco elastic and anticorrosive and the outer layer, which is the protective layer of polymeric material. The values of the internal and external pressures, leading to the destruction of the layers, are determined

Keywords: anticorrosive coating, displacement, deformation, stress, pressure, layer, condition of destruction

\section{1. Введение}

В последнее время широкое применение получили разного рода антикоррозионные покрытия. В большинстве случаев они имеют полимерную основу и поэтому проявляют вязкие свойства. Во избежание растекания полимера его «подкрепляют» лентой. Таким образом, конструкция становится трехслойной, причем средний слой является вязким. В таких конструкциях происходит перераспределение напряжений, которое приводит к изменению прочностных ее характеристик.

\section{2. Литературный обзор}

Целью данной работы является определение предельного состояния в трехслойном цилиндре, находящимся под действием внутреннего и внешнего давлений.

\section{3. Определение предельного состояния в трехслойном цилиндре}

Рассмотрим трехслойный цилиндр с внутренним радиусом $\mathrm{R}_{1}$ и внешним $\mathrm{R}_{2}$, находящийся под действием равномернораспределенной силы, приложеной к боковым поверхностям. Обозначим интенсивность силы, приложенной к внутренней поверхности через $\mathrm{P}_{1}$, а к внешней $-\mathrm{P}_{2}$. Так как антикоррозионное покрытие наносится на металлическую поверхность, то первый (внутренний) слой будем считать упругим. На этот слой действуют внутреннее давление $\mathrm{P}_{1}$ и сила со стороны покрытия. Интенсивность этой силы обозначим через $\mathrm{q}_{1}$. Предположим, что во всей конструкции осуществляется состояние плоской деформации, что верно для трубопроводов. Тогда, приняв предположение об ассиметричном поведении цилиндра и тонкостенности первого слоя имеем:

$$
w_{1}=\left(P_{1}-q_{1}\right) \frac{1-v_{1}^{2}}{E_{1}} \cdot \frac{R_{1}^{2}}{h_{1}},
$$

где $\mathrm{w}_{1}$-радиальное перемещение точек первого слоя; $\mathrm{E}_{1}$ - модуль Юнга; $\mathrm{v}_{1}$ - коэффициент Пуассона; $\mathrm{h}_{1}-$ толщина.

Аналогичная формула верна и для третьего (внешнего) слоя, если предположить, что «подкрепляющая» лента является упругой. Тогда имеем:

$$
w_{3}=\left(q_{2}-P_{2}\right) \frac{1-v_{2}^{3}}{E_{3}} \cdot \frac{R_{2}^{2}}{h_{2}},
$$

где $\mathrm{w}_{3}$ - прогиб точек третьего слоя; $\mathrm{E}_{3}$ - модуль Юнга; $\mathrm{v}_{3}$ - коэффициент Пуассона; $\mathrm{h}_{2}$ - толщина; $\mathrm{q}_{2}-$ интенсивность силы, действующей на третий слой со стороны покрытия.

Рассмотрим второй (средний) слой-покрытие, опираясь на гипотезу о несжимаемости. Тогда уравнения состояния для второго слоя можно представить в виде:

$$
\begin{aligned}
& \tilde{E} x l_{2}=\frac{3}{4}\left(\sigma_{2}-\sigma_{0}\right) ; \\
& \tilde{E} x l_{0}=\frac{3}{4}\left(\sigma_{0}-\sigma_{2}\right),
\end{aligned}
$$

где $\tilde{E}$ - оператор, который определяется следующим образом:

$$
\tilde{E} x f=E_{2}(1-R) f=E_{2}\left[f(t)-\int_{0}^{t} R(t-\tau) f(\tau) d \tau\right],
$$

где $\mathrm{E}_{2}$ - мгновенный модуль упругости $\mathrm{R}(\mathrm{t})$ резольвента ядра ползучести; $l_{2}, l_{0}$ - соответственно радиальная и окружная деформации; $\sigma_{2}, \sigma_{0}-$ радиальное и окружное напряжения соответственно; $\mathrm{t}$ - время.

Известно, что при принятых предположениях прочность несжимаемого тела определяется равенством

$$
w_{2}=\frac{c(t)}{r},
$$

где $\mathrm{r}$-текущий радиус; $\mathrm{c}(\mathrm{t})$ - неизвестная функция; $\mathrm{w}_{2}-$ прогиб точек второго слоя. 
Учитывая полученное соотношение и физический закон, уравнение равновесия можно записать в виде:

$$
\frac{\partial \sigma_{2}}{\partial r}+\frac{4}{3} \frac{1}{r^{3}} \tilde{E} x C(t)=0 .
$$

Откуда получаем

$$
\sigma_{2}=-\frac{2}{3} \cdot \frac{1}{r^{2}} \tilde{E} x C(t)+C_{1}(t),
$$

где $C_{l}(t)-$ неизвестная функция.

Для определения неизвестных величин $C_{l}(t)$ и $C(t)$ воспользуемся граничными условиями

$$
\begin{gathered}
\sigma_{2} / r=R_{1}=-q_{1} ; \\
\sigma_{2} / r=R_{2}=-q_{2} .
\end{gathered}
$$

Итак получим

$$
\begin{aligned}
& -\frac{2}{3} \frac{1}{R_{1}^{2}} \tilde{E} x C(t)+C_{1}(t)=-q_{1} ; \\
& -\frac{2}{3} \frac{1}{R_{2}^{2}} \tilde{E} x C(t)+C_{1}(t)=-q_{2} .
\end{aligned}
$$

Из этой системы

$$
C(t)=\frac{3}{2} \frac{R_{1}^{2} R_{2}^{2}}{R_{2}^{2} R_{1}^{2}} \tilde{E}^{-1}\left(q_{1}-q_{2}\right),
$$

где

$$
\tilde{E}^{-1} x f=\frac{1}{E_{2}}\left[f(t)+\int_{0}^{t} \Gamma(t-\tau) d \tau\right] .
$$

Таким образом, величину $\mathrm{w}_{2}$ можно определить, так же как и $\mathrm{w}_{1}$ и $\mathrm{w}_{2}$ через $\mathrm{q}_{1}$ и $\mathrm{q}_{2}$. Для определения этих величин воспользуемся контактными условиями на поверхностях $\mathrm{r}=\mathrm{R}$ и $\mathrm{r}=\mathrm{R}_{2}$. Предположим, что на этих поверхностях имеется полное сцепление, тогда

$$
\begin{aligned}
& W_{1}=W_{2} / 2=R_{1} ; \\
& W_{2} / 2=R_{2}=W_{3} .
\end{aligned}
$$

Итак, система для определения $\mathrm{q}_{1}$ и $\mathrm{q}_{2}$ имеет вид:

$$
\begin{aligned}
& \frac{1 v_{1}^{2}}{E_{1}} \frac{R_{1}^{2}}{h_{1}} P_{1} \quad q_{1} \quad \frac{3}{2} \frac{R_{1} R_{2}^{2}}{R_{2}^{2} R_{1}^{2}} \tilde{E}^{1} q_{1} \quad q_{2} ， \\
& \frac{1 v_{3}^{2}}{E_{3}} \frac{R_{1}^{2}}{h_{2}} q_{2} \quad P_{2} \quad \frac{3}{2} \frac{R_{1}^{2} R_{2}}{R_{2}^{2} R_{1}^{2}} \tilde{E}^{1} q_{1} q_{2} \text {. }
\end{aligned}
$$

Полученная система интегральных уравнений позволяет найти величины $\mathrm{q}_{1}$ и $\mathrm{q}_{2}$, а следовательно, через выражения (1)-(3) напряженно-деформированное состояние в произвольной точке конструкции.

Определим теперь предельное состояние. Под предельным состоянием в нашем случае будем понимать такое состояние, при котором начинается разрушение первого или третьего слоя по истечению большого значения времени. В этом случае, очевидно, необходимо в системе (4) перейти к пределу $t \rightarrow \infty$. Тогда из (4) получим:

$$
\begin{aligned}
& \frac{1 v_{1}^{2}}{E_{1}} \frac{R_{1}}{h_{1}} P_{1} \quad q_{1} \quad \frac{3}{2} \frac{R_{2}^{2}}{R_{2}^{2}} R_{1}^{2} E_{2} q_{1} q_{2} \quad \text { () } q_{1} q_{2} \text {, } \\
& \frac{1 v_{3}^{2}}{E_{3}} \frac{R_{2}}{h_{2}} q_{2} \quad P_{2} \quad \frac{3}{2} \frac{R_{1}^{2}}{R_{2}^{2}} R_{1}^{2} E_{2} q_{1} \quad q_{2} \quad \text { () } q_{1} q_{2} \text {, }
\end{aligned}
$$

где $\tilde{\Gamma}(\cdot)$ - образ Лапласа функции $Г(\mathrm{t})$ при стремлении переменной Лапласа к нулю. Отметим, что хотя величины q и q одной буквой, в системе (5) они обозначают переделы $\mathrm{q}_{1}$ и $\mathrm{q}_{2}$ при $t \rightarrow \infty$.

При написании системы (5) предполагалось, что $\tilde{\Gamma}(\cdot)$ существует.

$$
\left.\begin{array}{c}
\left.q_{1}=\frac{\frac{1-v_{1}^{2}}{E_{1}} \cdot \frac{R_{1}}{h_{1}} P_{1} \mid+\frac{3}{2} \frac{R_{2}^{2}}{R_{2}^{2}-R_{1}^{2}} E_{2}[1-\tilde{\Gamma}(\cdot)]\left(P_{2}+A P_{1}\right)}{\frac{3}{2} \frac{R_{2}^{2}}{R_{2}^{2}-R_{1}^{2}} E_{2}[1+\tilde{\Gamma}(\cdot)](1+A)+\frac{1-v_{1}^{2}}{E_{1}} \cdot \frac{R_{1}}{h_{1}}}:\right\} \\
\mathrm{q}_{2}=\mathrm{P}_{2}+\mathrm{A}\left(\mathrm{P}_{1}-\mathrm{q}_{1}\right),
\end{array}\right\}
$$

где

$$
A=\frac{E_{2}\left(1-v_{1}^{2}\right)}{E_{1}\left(1-v_{3}^{2}\right)} \cdot \frac{h_{2}}{h_{1}} \cdot \frac{R_{2}^{3}}{R_{1}^{3}} .
$$

Теперь определим нагрузки, приводящие к разрушению первого слоя. Для тонкостенных труб за критерий разрушения можно взять условие $\sigma_{\theta}=\sigma_{p}$ так как $\sigma_{2}<<\sigma_{0}$, где $\sigma_{p}$ - некоторое напряжение, приводящее к разрушению. Тогда для первого слоя условие (7) примет вид

$$
p_{1}-q_{1} \sigma_{p}^{(1)} \frac{h_{1}}{R_{1}} \text { или } p_{1}=q_{1}+\sigma_{p}^{(1)} \frac{h_{1}}{R_{1}} \text {. }
$$

Отметим, что из (7) можно определить и $\mathrm{p}_{2}$, что было бы целесообразно при проектировании подводных трубопроводов. Тогда для внешнего слоя имеем

$$
q_{2}-p_{2}=\sigma_{p}^{(2)} \frac{h_{2}}{R_{2}} \text { или } p_{2}=q_{2}-\sigma_{p}^{(2)} \frac{h_{2}}{R_{2}} \text {. }
$$

Составляя выражения (8) и (9), при заданных параметрах цилиндра, можно определить вид предельного состояния.

\section{4. Выводы}

1. Определены значения внутреннего и внешнего давлений, приводящие к разрушению соответственно внутреннего и внешнего слоев.

2. С увеличением внутреннего радиуса значение внутреннего давления, приводящее к разрушению первого слоя, уменьшается, а с увеличением толщины - увеличивается.

3. С увеличением внешнего радиуса значение внешнего давления, приводящее к разрушению внешнего слоя увеличивается, а с увеличением толщины уменьшается.

\section{Литература}

1. Санжаровский, В. Т. Физико-механические свойства полимерных лакокрасочных покрытий [Текст] / 
В. Т. Санжаровский. - Москва: Издательство «Химия», 1970. $-370 \mathrm{c}$.

2. Седов, Л. И. Механика сложной среды. Т. 1 [Текст]/

Л. И. Седов. - Москва: Издательство, 1970. - 492 с.

3. Работнов, Ю. Н. Ползучести элементов конструкций [Текст] / Ю. Н. Работнов. - Москва: «Наука», 1966. - 780 с.

4. Москвитин, В. В. Сопротивление вязко-упругих материалов [Текст] / В. В. Москвитин. - Москва: Издательство «Химия», 1972. - 370 с.

5. Амензаде, Ю. А. Теория упругости [Текст] / Ю. А. Амензаде. - Москва: Издательство «Высшая школа», 1976. -287 c.

6. Бугаков, И. И. Ползучесть полимерных материалов [Текст] / И. И. Бугаков. - Москва: Издательство "Наука", 1973. - 287 с
References

1. Sanzharovskij, V. T. (1970). Fiziko-mehanicheskie svojstva polimernyh lakokrasochnyh pokrytij. Moskow: Izdatel'stvo «Himija», 370.

2. Sedov, L. I. (1970). Mehanika slozhnoj sredy. Vol. 1. Moskow: Izdatel'stvo, . - $492 \mathrm{~s}$.

3. Rabotnov, Ju. N. (1966). Polzuchesti jelementov konstrukcij. Moskow: «Nauka», 780.

4. Moskvitin, V. V. (1972). Soprotivlenie vjazkouprugih materialov. Moskow: Izdatel'stvo «Himija», 370.

5. Amenzade, Ju. A. (1976). Teorija uprugosti. Moskow: Izdatel'stvo «Vysshaja shkola», 287.

6. Bugakov, I. I. (1973). Polzuchest' polimernyh materialov. Moskow: Izdatel'stvo "Nauka", 287.

Рекомендовано до публікації д-р техн. наук, проф. Гасанов Р. А. Дата надходження рукопису 23.01.2015

Хейрабади Газаля Сабир кызы, асистент, кафедра "Прикладная механика", Азербайджанская Государственная Нефтяная Академия, ул. Кадырли, 75, г. Баку, Азейрбаджан, AZ106

E-mail:qezale@mail.ru

УДК 656.211

DOI: $10.15587 / 2313-8416.2015 .36936$

\title{
МЕТОД ВИЗНАЧЕННЯ УБЕЗПЕЧЕНОЇ ЗОНИ ВИКОНАННЯ РОБІТ НА КОЛІЯХ ЗАЛІЗНИЧНИХ СТАНЦІЙ
}

\author{
(C) С. О. Змій, В. П. Мороз
}

Розроблений метод визначення убезпеченої зони виконання робіт на коліях станції, який засновано на геометричному представленні колійного розвитку, має на меті обтрунтувати необхідність виконання оповіщення та убезпечення працівників при переміщенні рухомого складу по суміжній з зоною виконання робіт колії. Отримані результати рекомендовано для використання у системах автоматичного оповіщення прачівників залізничного транспорту

Ключові слова: колійний розвиток, геометрична модель колійного розвитку, убезпечена зона виконання робіт, габарит зони виконання робіт, габарит наближення будівель

The developed method for determining of safe work areas on the tracks station, which is based on geometric representation of trackage, aims to justify the need to carry insurance and alert staff when moving rolling stock on the area adjacent to the track works. The results are recommended for use in automatic alerts of railway transport workers

Keywords: Track development, geometric model of trackage, protected area of work, size of work area, structure clearance gauge

\section{1. Вступ}

Для убезпечення працівників, що виконують роботи на коліях залізничних станцій, необхідно своєчасно виявити небезпеку, яку створює при переміщенні рухомий склад та своєчасно їх про це оповістити. На даний час, в основному, на станції задачу оповіщення виконує черговий по станції

При проведенні дослідження відповідних дій чергових по станції та алгоритмів функціонування існуючих систем автоматичного оповіщення встановлено, що при переміщенні рухомого складу по суміжній 3 зоною виконання робіт колії не існує науково обгрунтованих вимог необхідності оповіщення та убезпечення цих працівників. Таким чином, роботи на коліях станції можуть бути, як необгрунтовано припинені без відсутності небезпеки з боку рухомого складу, так і не убезпеченні за відсутності необхідного оповіщення.

\section{2. Постановка проблеми}

На теперішній час відсутній науково обгрунтований метод, що дозволяє однозначно визначити необхідність виконання оповіщення працівників на коліях станції при переміщенні рухомого складу по суміжній з зоною робіт колії.

Для рішення поставленої проблеми необхідно вирішити наступні задачі:

- визначення убезпеченої зони виконання робіт на коліях;

- визначення умов убезпеченого виконання робіт при переміщенні рухомого складу по суміжній колії з зоною робіт.

\section{3. Літературний огляд}

Проблемам убезпечення виконання робіт на коліях залізничних станцій присвячено значну кількість робіт. У діючих правилах технічної експлуатації [1] та стандарті [2] регламентовано лише загальні умови необхідності оповіщення. У 